\title{
Study on the Communication Problems and Countermeasures of TCM Culture under the Vision of Healthy China
}

\author{
Zhou Ping ${ }^{1, a}$, Zhu Danni ${ }^{2, b^{*}}$ \\ ${ }^{1}$ Department of Journalism and Communication, School of the Humanities, Jianghan University, Wuhan, Hubei, \\ China \\ ${ }^{2}$ Department of Journalism and Communication, School of the Humanities, Jianghan University, Wuhan, Hubei, \\ China \\ a496805869@qq.com \\ $b^{*}$ 2860729074@qq.com
}

\begin{abstract}
Combined with the present status of development of TCM and the idea of "Healthy China", this paper analyzes the main problems existing in the communication of TCM culture and the corresponding countermeasures.The countermeasures include the TCM education popularization strategy, the effective promotion strategy of TCM culture and the TCM culture brand building strategy. The healthy development of TCM culture needs the joint efforts of the government, the market, the media industry and other aspects.
\end{abstract}

Keywords: Healthy China, TCM culture, communication, countermeasures

\section{“健康中国” 视域下中医文化传播的 问题与对策研究}

周平 $1, \mathrm{a}$ 祝丹妮 $2, \mathrm{~b}^{*}$

江汉大学人文学院新闻传播学系, 武汉, 湖北, 中国

江汉大学人文学院新闻传播学系, 武汉, 湖北, 中国

a496805869@qq.com

b*2860729074@qq.com

摘要

本文围绕中医文化近年来的发展现状，结合 “健康中国” 理念，分析了中医文化传播存在的主要问题，提出了 三方面对策，即中医教育普及策略、中医文化有效推广策略和中医文化品牌塑造策略。我国中医文化的健康发 展需要政府、市场以及行业等各方面的共同努力。

关键词: 健康中国，中医文化，传播，对策

\section{1. 前言}

中医文化作为独具特色的中华文明宝贵遗产， 凝聚着祖先的智慧。千百年来, 其独特的医学理念 和治疗方式, 代代相传, 提供了人类面对疾病的重 要治疗思路。2020 年爆发的新冠肺炎疫情中, 中药
莲花清瘟颗粒对治疗和预防肺炎的显著疗效备受各 界关注。“中医药医治的核心作用, 是能显著且有 效的降低轻症病人发展为重症病人的几率。对改善 发热、咳嗽、乏力等症状，中药见效非常快。” [1]

另一方面，中医药文化也契合了人类健康生活 的永恒需求, 建立了普范的疾病预防和健康养生观, 
并在当下 “健康中国” 理念的推进中起到了不可忽 略的作用。“健康中国” 理念最早在新世纪初被提 出, 后经过党中央、国务院组织各界不断修改完善, 最终通过文件《健康中国行动（2019-2030 年）》 向社会颁行。其指导思想为：坚持以人民为中心， 树立 “大卫生、大健康” 理念, 坚持预防为主、防 治结合的原则, 中西医并重, 政府、社会、个人协 同推进, 建立健全健康教育体系, 促进以治病为中 心向以健康为中心转变, 提高人民健康水平。 ${ }^{[2]}$

\section{2. 中医文化与 “健康中国” 理念的关系}

探讨中医文化的内涵, 可从其理论核心 “阴阳 学说” 入手。在自然界中, “阳为光, 阴为暗, 昼 为阳, 夜为阴, 阳生则阴降。” ${ }^{[3]}$ 阴阳是一个相互 依存、制约、转化的过程, 只有阴阳平衡, 才能使 人体获得健康, 使社会和谐发展。因此中医文化提 倡 “治未病”, 如冬病夏治、夏病冬治、预防胜于 治疗等。“健康中国” 虽然是一个创新型发展的理 念, 却与传统中医文化对人类社会整体健康和谐发 展的追求相契合。二者本身就是一种互相促进、共 同发展的关系。

首先, “健康中国” 所秉持的 “预防为主, 防 治结合” 原则是在中医文化核心理念基础之上的延 伸。国内医学卫生领域所遵循的 “预防为主” 的策 略思维就源于古代中医学著作《黄帝内经》 “不治 已病治未病” 这一思想。由于慢病的养成来源于人 们长期亚健康的生活习惯, 所以, 运用好中医治疗 慢病的独特理念、文化和方式, 就能够提高人们日 常的养生保健水平, 有效预防慢病的发生, 推动人 类健康水平的发展。

其次, 中医在临床治疗的实践中始终贯穿着“预 防” 的概念。相对于西医, 中医治病, 着眼于人身 体的整体，甚至是时间上的整体，从病人的过去、 现在、未来三个角度去考虑患者的身体情况。优秀 的中医甚至会从患者当下及过去的生活经历、性格、 生活习惯中寻找疾病的根源, 主动预防可能出现的 潜在问题并关注患者往后终生的生活质量与寿命。

再次, 大力弘扬中医文化能够提高人们日常养 生保健意识, 减少慢病的发病率, 提高全民健康素 养水平, 达到 “健康中国” 的总体目标。中医对治 疗慢病有奇效, 它看重生病的根源和途径, 以及病人 的体质，将病邪作为身体的资源和能量以为已用。 “好” 与 “坏” 并存, “好” 与 “坏” 相互转化, 实现健康平衡。

最后, “健康中国” 能够为中医文化的传播提 供更宽广的平台。“健康中国” 虽然是一个创新型 发展的理念, 却与传统中医文化对人类社会整体健 康和谐发展的追求相契合。因此, 中医文化可以借 助 “健康中国” 政策的指导思想、基本路径和总体 目标, 通过相关教育、有效推广以及相关品牌的塑 造等途径, 让自身得到全民的、联动的和有效的传
播, 从而推动 “健康中国” 的整体进程。

\section{3. 中医文化的传播现状与问题}

\section{1. 中医文化的传播现状}

我们可借用美国著名传播学家哈罗德 - 拉斯韦 尔的 “ $5 \mathrm{~W}$ ” 理论 ${ }^{[4]}$ 来分析近年来中医文化的传播现 状。“ “5W” 即传播的五个根本要素：传播者、传播 内容、传播媒介、信息受众和传播效果。

从传播者层面来看, 中医文化的传播者呈现出 了多样化的特点, 主要包括与中医相关的医疗与教 育机构、政府部门、专业媒体等秩序性传播者。融 媒体时代，信息的传播突破了时间与空间的限制， 通过 “两微一端”，人人都成为中医文化的传播者 和创造者。

从传播内容层面来看, 当前主要为中医健康养 生理论、中医处方医案和医学典籍三大类。其中, 中医健康养生理论最受人民群众喜爱，代表着权威 的医学典籍的传播频率最高。即时的、多样的、灵 活的、个性化的传播活动, 大大增强了中医文化的 影响力。

从传播媒介层面来看, 较常用的中医文化传播 方式主要包括电视、微信、微博、头条、短视频、 音频 APP 等渠道。其中, 微博已经成为人们获取中 医文化的重要渠道。微信用户则主要通过订阅号的 推送获取中医文化内容, 或者通过微信群、朋友圈 的分享, 形成中医文化的社群传播。短视频类中医 养生的传播则更擅于打造专家形象人设, 短短几分 钟由 “专家” 阐述健康养生知识, 很受欢迎。

从信息受众层面和传播效果来看，信息受众与 传播者间的界限不够清晰, 但总体呈现出了年龄群 体分化的特征。有研究结果表明, 老年群体对中医文 化的认可程度显著高于青年群体, 但青年群体在了 解中医知识方面具有较高的诉求。从传播效果来看, 中医类健康科普短视频点击率最高; 但有些借势营 销或 “标题党” 的微信文章, 影响了受众对中医文 化的印象。

综上所述, 目前中医文化的传播现状势头良好, 但并未受到足够规范的引导。中医文化的传播总体 而言还不够主动。即使传播者、传播方式、传播内 容相较从前都更加多样化, 但并未起到革命性的作 用。

\section{2. 中医文化传播凸显的问题}

\section{2. 1. 传播内容: 专业性不足}

国家 “健康中国” 的推行以及当代人们对健康 养生的追求让很多人看到了大健康产业的蓝海。但 一些 “挂羊头卖狗肉” 所谓的 “健康机构” 层出不 
穷; 针对以老年人等弱势群体为主、打着 “中医养 生” 旗号的保健品骗局事件屡屡发生; 新媒体的便 利使得传播的中医文化质量参差不齐，鱼龙混杂， 等等。

之所以如此, 原因很复杂, 最主要为: 第一, “把关人” 的缺失。相关部门监管力度不够、监管 制度和措施不完善, 让 “健康骗子” 有机可乘, 使 中医沾上了 “浑水”。第二, 权威媒体发声不够。 官方媒体对中医文化的宣扬力度不够, 让鱼龙混杂 的自媒体钻了空子。第三，中医专业性人才培养不 足。譬如当前, 我国中医专业院校大多削弱了学生 对中医古籍的学习, 将其从必修改为选修, 降低了 中医专业学生毕业的难度, 同时也降低了中医人才 “专家率”。普通受众也无法辨识 “真中医” 和 “伪 中医”。

\subsection{2. 传播方式: 缺乏体验感与互动性}

目前中医文化的传播主要是以单向传播为主, 受众缺乏情景感的体验。中医文化的传播方式主要 以线上为主, 但无论微信、微博、头条, 还是短视 频、音频 APP, 都无法做到实时性的中医健康体验。 通过新媒体传播, 受众虽然可以便捷的跨越时空接 收信息，但相对于中医 “望闻问切” 面对面的诊断 传统, 从中获得的触感和疗效颇微。

如果说体验感重视的是物理身体接触, 互动性 则更强调精神交流与思想碰撞。在当前中医药文化 的互动中, 仅靠网络上的一些碎片化留言与反馈, 受 众无法对其产生深度交流的欲望, 更难以对神奇的 中医药文化产生情感共鸣。

从某种意义上来说, 互动性缺乏的问题实际上 也是认同感缺乏的问题。大数据的推送功能只让相 关信息在一部分接触过的人群更容易获得, 却在更 多人群中缺少曝光度。如何针对不同群体的个性化 特征, 运用喜闻乐见的内容与形式, 以及线上线下 联动增加接触率, 让中医文化变成一种新的时尚文 化, 增强各群体对中医文化的认同感, 从而产生情 感依附和行动选择, 是当前亟待解决的主要问题。

\section{4. “健康中国” 视域下中医文化的全民传播 策略}

\section{1. 中医教育普及策略}

在政府的支持和倡导的前提下, 中医教育的普 及首先要从社会群体的两个基本单位开始, 一是学 校, 二是社区。通过对学校、社区实施相关措施, 能够有效提升中医文化传播内容的专业性、提高大 众对中医文化的辨别能力。

从学校角度看, 如何通过教育打造中医专业人 才呢? 教育与学科相关。中医是集理论与实际、基 础与临床为一体的学科, 中医教育应当根据其学科
特性作出适当调整, 不能急功近利。在课程设置中 应当重视中医经典内容, “思求经旨” “演其所知” ${ }^{[5]}$, 学习经典, 融会贯通。从制度层面来说, “中 西医结合” 的理念应落到实处。攻读西医的学生懂 中医, 专攻中医的学生懂西医, 非医科的学生通过 mooc 修读中医金课, 如此, 不仅能够扩大中医文化 的普及, 提升国人日常保健意识, 更能促进中西医 文化之间的交流与发展, 最终有利于人类健康生活 品质的提升。

另一方面, 可在社区开展中医文化教育普及推 广活动。比如, 加强社区中医教育基础设施的建设。 利用好社区的文化宣传栏, 定期更新, 形成 “中医 主题文化周”; 与辖区专业机构合作，成立中医健 康服务中心，让中医随时触手可及。还可以在社区 内开展中医药文化主题教育实践活动。在不同季节 与节气因时因地举办中医健康讲座和实践练习, 让 中医理念融入人们日常生活, 潜移默化改变人们的 生活方式。此外, 组建社区中医兴趣社团, 让居民 们主动参与中医文化活动的策划与交流; 组织中医 志愿服务活动, 弘扬中医文化优良风尚。等等。这 些措施都可增强居民对中医文化活动的参与度和认 同感，同时也促进了社区文化建设，建立和谐邻里 关系, 形成大健康环境。

\section{2. 中医文化有效推广策略}

\subsection{1. 政府: 适时打击+正确引导}

针对中医文化传播 “专业性不足” 的市场乱象, 政府一方面要主导建立健全中医文化传播机制和监 管制度，严查借中医进行虚假宣传的私营、民营医 院及企业、媒体; 同时, 政府也应当塑造中医意见 领袖的权威形象, 通过各类官方媒体平台塑造优质 栏目，传播中医文化信息，正本清源，适时适当引 导好舆论方向, “谣言”与 “流言” 自然不攻自破。

\subsection{2. 市场: 合理跨界十健康营销}

中医文化要得到有效推广, 单靠政府的管理与 引导远远不够。有些学者认为, 当代中医文化的商 业性太过浓厚，导致受众反感，因此中医文化传播 不应染上商业气息。笔者对此并不完全认同。中医 文化的推广不应将商业利益全盘否定, 而要在不逾 越道德与法律的前提下, 让企业充分发挥自身的市 场敏锐度和积极性, 合理开展中医文化营销, 大胆 创新中医文化表现形式, 最终实现国家、企业与受 众共赢的局面。

\subsection{3. 行业：健康管理+中医医养}

在我国大健康行业领域中, 健康管理已成为新 趋势。将中医药与健康管理相结合, 聚焦各类人群 特别是中老年人的慢病康复, 从科学与养生的角度, 为患者量身定制中医特色的健康管理方案。如动态 
健康大数据监控服务、饮食平衡数据监控服务、睡 眠平衡数据监控服务、心理平衡数据监控服务等等。 此外, 还可以建立在线诊疗 App, 就近整合中医资 源、疾病实时在线咨询、中医养生保健知识库等, 以此真正实现中医医养结合, 有效提升人们的生命 质量与幸福感。

\section{3. 中医文化品牌塑造策略}

大国文化要有品牌, 中医文化的品牌塑造首当 其冲应当从我国最权威的媒体开始。打造一些中医 养生品牌节目, 或结合时令提醒养生要点, 或关注 专题保健话题, 或解答健康小烦恼, 内容要接地气。 可配以名老中医专家出镜发声, 或是中医历史的系 列纪录片, 每天同 “天气预报” 般准时播出, 让受 众通过日积月累, 建立对中医文化品牌的认知。国 家级媒体对中医文化的正向引导也能给地方媒体、 影视公司、自媒体提供新方向。尤其要重视通过流 量大的短视频平台讲好中医故事、传播好健康理念, 甚至向世界传播, 将中医文化品牌打造成独具中国 特色的大国名片。

\section{5. 结论}

“健康中国” 理念与中医文化对人类社会整体 健康和谐发展的追求相契合, 二者是一种互相促进、 共同发展的关系。在 “健康中国” 视域下, 中医药文 化的发展与传播已迎来新的机遇和挑战。通过中医 教育普及策略、中医文化有效推广策略和中医文化 品牌塑造策略, 能较好地传播好中医文化。当然, 中医文化的传播不能仅靠个人或个别机构, 而需要 全社会共同发力, 各司所职, 努力增强人们日常养 生保健意识, 减少慢病的发病率, 提高全民健康素 养水平, 最终达到 “健康中国” 的总体目标, 也推 动人类健康水平的发展, 为世界贡献力量。

\section{REFERENCES}

[1] Xinhuanet.(2019)Taking People's health as the center -- Interpretation of "Healthy China"action.http://www.xinhuanet.com/politics/ 2019-07/16/c_1124760864.htm.

[2] National Health Commission of the PRC.(2019) "Healthy China"campaign 2019-2030. http://www.gov.cn/xinwen/2019-07/15/content_5 409694.htm.

[3] Gao, X.Y.(2002) Chinese dictionary of acupuncture and moxibustion. Henan Science and Technology Press., Zhengzhou. pp.76.

[4] Lasswell.H. D.(2013)the Structure and Function of Social Communication .Communication University of China press.,Beijing.pp216-228.
[5] Zhang,Z.J.(2012)Treatise on Febrile Diseases. Thread-Binding Books Publishing House., Beijing.pp2. 